\title{
Atmospheric parameters in a subtropical cloud regime transition derived by AIRS and MODIS: observed statistical variability compared to ERA-Interim
}

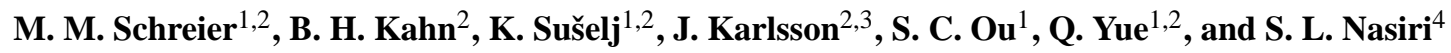 \\ ${ }^{1}$ Joint Institute for Regional Earth System Science and Engineering, University of California - Los Angeles, \\ Los Angeles, CA, USA \\ ${ }^{2}$ Jet Propulsion Laboratory, California Institute of Technology, Pasadena, CA, USA \\ ${ }^{3}$ Department of Meteorology and Bolin Centre of Climate Research, Stockholm University, Sweden \\ ${ }^{4}$ Department of Atmospheric Sciences, Texas A\&M University, College Station, TX, USA \\ Correspondence to: M. M. Schreier (mathias.schreier@jpl.nasa.gov)
}

Received: 18 July 2013 - Published in Atmos. Chem. Phys. Discuss.: 12 September 2013

Revised: 14 February 2014 - Accepted: 18 February 2014 - Published: 9 April 2014

\begin{abstract}
Cloud occurrence, microphysical and optical properties, and atmospheric profiles within a subtropical cloud regime transition in the northeastern Pacific Ocean are obtained from a synergistic combination of the Atmospheric Infrared Sounder (AIRS) and the MODerate resolution Imaging Spectroradiometer (MODIS). The observed cloud parameters and atmospheric thermodynamic profile retrievals are binned by cloud type and analyzed based on their probability density functions (PDFs). Comparison of the PDFs to data from the European Centre for Medium Range Weather Forecasting reanalysis (ERA-Interim) shows a strong difference in the occurrence of the different cloud types compared to clear sky. An increasing non-Gaussian behavior is observed in cloud optical thickness $\left(\tau_{\mathrm{c}}\right)$, effective radius $\left(r_{\mathrm{e}}\right)$ and cloud-top temperature $\left(T_{\mathrm{c}}\right)$ distributions from stratocumulus to trade cumulus, while decreasing values of lowertropospheric stability are seen. However, variations in the mean, width and shape of the distributions are found. The AIRS potential temperature $(\theta)$ and water vapor $(q)$ profiles in the presence of varying marine boundary layer (MBL) cloud types show overall similarities to the ERA-Interim in the mean profiles, but differences arise in the higher moments at some altitudes. The differences between the PDFs from AIRS+MODIS and ERA-Interim make it possible to pinpoint systematic errors in both systems and help to understand joint PDFs of cloud properties and coincident thermodynamic profiles from satellite observations.
\end{abstract}

\section{Introduction}

Earth's cloud types are highly variable in both their frequency of occurrence and optical properties, and therefore have strong relevance to climate sensitivity (see, e.g., Cess et al., 1989, 1996; Bony and DuFresne, 2005; Wyant et al., 2006; Vial et al., 2013; or IPCC, 2007). The spatial and temporal variation in cloud types are controlled to a significant degree by the large-scale atmospheric dynamic circulation and thermodynamic structures (Stephens, 2005; Bony and Dufresne, 2005; Su et al., 2008) in combination with variations of water vapor (Stevens, 2005). However, on a smaller scale, the water vapor within clear-sky conditions can be influenced by adjacent clouds (Stevens, 2005), resulting in variations of water vapor. Quantifying the variations of potential temperature $(\theta)$ and water vapor $(q)$ profiles within each cloud type is therefore essential for understanding the spatial and temporal variability of clouds in a present and future climate. There is also an increased interest in the analysis of joint probability distribution functions (PDFs) of parameters such as $\theta$ and total water content $q_{\mathrm{t}}$, which could be used to develop subgrid-scale climate model parameterizations to represent variability within a general circulation model (GCM) grid. Based on early ideas (Sommeria and Deardorff, 1977; Cuijpers and Bechthold, 1995), the importance of cloud-dependent statistics for $\theta$ and $q$ has been pointed out by, for example, Pincus and Klein (2000), Larson et al. (2001), Gierens et al. (2007), Pressel and Collins (2012), 
Quaas (2012) and Randall (2013). Recent studies such as those by Guo et al. (2010) and Bogenschutz et al. (2013) have been various attempts to implement and improve such schemes in climate models.

Satellite data and reanalysis data might be a helpful tool in the investigating of PDFs of cloud regimes in remote regions. A particular remote area of cloud regime transition is the stratocumulus $(\mathrm{Sc})$ to trade cumulus (trade $\mathrm{Cu}$ ) transition (Hartmann et al., 1992; Teixeira et al., 2011). This region is thought to be a significant contributor to uncertainty in the magnitude of climate sensitivity in global climate models and it is still a matter of debate as to which portion of cloudiness within this area dominates the uncertainty in climate sensitivity (Cess et al., 1989; Wood and Bretherton, 2006; Medeiros et al., 2008). The radiative feedbacks of the various types of marine boundary layer (MBL) clouds show large variations between different GCM simulations (Williams and Webb, 2009). Therefore, detailed observations of cloud properties, thermodynamic profiles and spectral radiances including their means, variances and higher order statistical moments are necessary to establish meaningful constraints for climate modeling efforts (Weber et al., 2011).

In situ observations are sparse in this area (Albrecht et al., 1995; Norris, 1998; Price and Wood, 2002; Tompkins, 2003), or based on limited time periods such as the Second Dynamics and Chemistry of Marine Stratocumulus field study (DYCOMS-II; Stevens et al., 2003) or the Marine ARM GPCI Investigation of Clouds (MAGIC; Lewis al., 2012). Therefore, the main source of $\theta$ and $q$ information is from reanalysis data such as ERA-Interim. Our aim is to validate information from these reanalysis profiles with contemporary A-train satellite data. Furthermore, we are interested in whether the satellite data provide additional quantitative information regarding the higher moments of the PDFs that the reanalysis may be lacking. There are systematic biases in the ERA-Interim low-latitude cloud regimes that have been previously discussed (Dee et al., 2011). In particular, the version of the Integrated Forecast System (IFS) most similar to that used in ERA-Interim (CY31R1) overestimates the population of trade cumulus while underestimating the cloud fraction, and has a high-altitude bias relative to the CloudAerosol Lidar and Infrared Pathfinder Satellite Observation (CALIPSO) lidar (Ahlgrimm and Köhler, 2010).

Infrared and microwave satellite sounders are capable of continuously observing the global oceans on a daily basis, albeit with coarser spatial and temporal resolution, as well as reduced precision and accuracy, compared to in situ observations. An example of these satellite sounders is the Atmospheric Infrared Sounder (AIRS)/Advanced Microwave Sounding Unit (AMSU) (Aumann et al., 2003), onboard the Earth Observing System (EOS) Aqua satellite, which has been operational since September 2002. AIRS/AMSU is an advanced sounding suite designed to retrieve temperature and water vapor profiles in clear and cloudy skies for cloud amounts up to and exceeding $70 \%$ (Susskind et al., 2006;
Yue et al., 2011). The use of infrared retrievals in the lower troposphere remains a challenge due to the decreasing information content and the difficulty in detecting low-cloud contamination. However, recent investigations (e.g., Kahn et al., 2011b; Martins et al., 2011, Yue et al., 2013) have shown that AIRS/AMSU is capable of observing coarse-layer thermodynamic structures in the planetary boundary layer.

Together with the MODerate resolution Imaging Spectroradiometer (MODIS; Barnes et al., 1998), also onboard EOS Aqua, it is possible to observe and estimate clouds with high spatial resolution $(\sim 1-5 \mathrm{~km}$, depending on the derived geophysical product) yielding sub-footprint information about cloud variability within the AIRS/AMSU field of view (FOV). Combining the information obtained from the two sensors has resulted in advances in cross-sensor radiance calibration (Tobin et al., 2006; Schreier et al., 2010), synergistic multi-sensor cloud property retrievals $(\mathrm{Li}$ et al. 2004a, b) and cloud phase characterization (Kahn et al., 2011a). It is also a useful source of information for radiative transfer calculations under cloudy conditions (Ou et al., 2013) and offers a promising basis for improvements in thermodynamic profile sounding (e.g., Maddy et al., 2011).

The synergistic use of AIRS and MODIS offers a unique opportunity to characterize simultaneous PDFs of $\theta, q$ and cloud properties - including optical thickness $\left(\tau_{\mathrm{c}}\right)$, effective radius $\left(r_{\mathrm{e}}\right)$ and cloud-top temperature $\left(T_{\mathrm{c}}\right)$ - and quantify relationships between these variables as a function of cloud type. In this study, we compare similarly derived PDFs from satellite data and the ERA-Interim reanalysis that are organized by cloud type.

The coarse horizontal resolution of AIRS/AMSU is a fundamental weakness. The remote sensing data $(\sim 45 \mathrm{~km})$ are only a factor of $\sim 2$ higher than ERA-Interim resolution $(\sim 80 \mathrm{~km})$. While it is impossible to resolve very small scale features that will be effectively smeared over the $45 \mathrm{~km}$ field of regard, the reanalysis is also subject to the assumptions imposed by subgrid-scale parameterizations, for which the satellite data are not subject to. Thus, there is value in comparing the two data sets. In this work, we examine whether the remote sensing observations of $\theta, q$ and cloud property PDFs are comparable to current state-of-the-art reanalysis data, especially in the case of the stratocumulus $(\mathrm{Sc})$ to trade cumulus (trade $\mathrm{Cu}$ ) transition. The level 2 satellite products are compared to identical PDFs obtained from the ERAInterim reanalysis to quantify similarities and differences depending on cloud type.

The paper is organized as follows. The AIRS thermodynamic soundings and MODIS cloud properties are described in Sect. 2, together with the ERA-Interim data. Section 3 discusses the cloud-type statistical distributions of these properties, including the mean, variance, skewness and kurtosis of observed cloud parameters and a comparison with ERAInterim data. Lastly, a discussion and summary are presented in Sect. 4. 


\section{Methodology}

\subsection{AIRS and MODIS observations}

The EOS Aqua platform has a polar Sun-synchronous orbit with an equatorial local crossing time of 01:30 (descending) and 13:30 (ascending). AIRS is a grating spectrometer with a spectral resolution of $v / \Delta v \approx 1200$, a total of 2378 channels in the range of 3.7-15.4 $\mu \mathrm{m}$ with a few spectral gaps, and well-calibrated level 1B radiances (Overoye, 1999). The AIRS FOV is approximately $1.1^{\circ}$, resulting in a footprint size of $13.5 \mathrm{~km}$ at nadir view. There are 90 cross-track scan angles with the highest at $\pm 48.95^{\circ}$, yielding a swath width of approximately $1650 \mathrm{~km}$. AIRS is co-registered with AMSU (Lambrigtsen and Lee, 2003), and the combination is used to retrieve $T, q$ and numerous other surface and atmospheric parameters. Geophysical retrievals are obtained in clear sky and broken cloud cover using a cloud-clearing methodology (Susskind et al., 2003).

The MODIS instrument is a spectrometer based on a spectral filter aperture with 36 channels in the range of $0.4-14 \mu \mathrm{m}$ and bandwidths of $0.01-0.5 \mu \mathrm{m}$, depending on the channel, and scans up to $\pm 55^{\circ}$ off nadir view. The pixel size depends on the channel and varies from $0.25-1.0 \mathrm{~km}$ at nadir. At $1 \mathrm{~km}$ resolution, there are 1354 cross-track pixels resulting in a swath width of approximately $2330 \mathrm{~km}$. Several MODIS algorithms are designed to obtain a wide variety of land, ocean and ice surface characteristics, as well as atmospheric and oceanic geophysical properties that include numerous cloud and aerosol parameters. In this work, we use collection 5 cloud products, including the cloud mask (Ackerman et al., 2008; Frey et al., 2008), effective radius $\left(r_{\mathrm{e}}\right)$ and optical thickness $\left(\tau_{\mathrm{c}}\right)$ (Platnick et al., 2003), and cloud-top temperature $\left(T_{\mathrm{c}}\right)$ (Menzel et al., 2006).

The MODIS pixels are accurately collocated within the AIRS FOV using the AIRS spatial response functions obtained from prelaunch calibration activities (Schreier et al., 2010). Since AIRS and MODIS have FOV sizes of $1.1^{\circ}$ and $0.08^{\circ}$ at nadir, respectively, this yields approximately 200 $1 \mathrm{~km}$ pixels of MODIS within a given AIRS FOV. Using this collocation technique, the importance of each MODIS pixel can be weighted depending on its location within the AIRS spatial response function (Nasiri et al., 2011).

\subsection{ERA-Interim reanalysis}

The ERA-Interim reanalysis is used as a comparison standard to the satellite observations. The reanalysis is an "interim" following ERA-40 (Uppala, et al., 2005), a meteorological reanalysis that uses a wide variety of observations that include synoptic weather information, radiosondes, satellite data and model forecast data produced by the European Centre for Medium-Range Weather Forecasts (ECMWF). The forecast model is the ECMWF Integrated Forecast System (IFS). While satellite data are used in the reanalysis, pri- marily clear-sky AIRS or High Infrared Radiometer Sounder (HIRS) radiances are used; for more details see Dee et al. (2011). The reanalysis spatial resolution is based on a T255 truncation scheme, resulting in $\sim 79 \mathrm{~km}$ grid spacing on a reduced Gaussian grid, making it somewhat larger than the AIRS/AMSU footprint at nadir. The time steps of calculation are $30 \mathrm{~min}$, with an output frequency of $6 \mathrm{~h}$. Cloud-top parameters $\left(T_{\mathrm{c}}, r_{\mathrm{e}}, \tau_{\mathrm{c}}\right.$ and cloud cover) from ERA-Interim were obtained in a manner that mimics the satellite observations and is consistent with the parameterizations in ERAInterim. First, the $r_{\mathrm{e}}$ and $\tau_{\mathrm{c}}$ are calculated on each of the ERA-Interim levels using the same formulations as in reanalysis model parameterization (see IFS documentation, 2007); that is, the $r_{\mathrm{e}}$ is parameterized as a linear function of height and equals $10 \mu \mathrm{m}$ at the surface and $45 \mu \mathrm{m}$ at the top of the atmosphere (which is taken to be $20 \mathrm{~km}$ ). The optical thickness is parameterized as a function of the liquid water amount in a vertical level $\left(U_{\mathrm{LWP}}\right)$ and $r_{\mathrm{e}}$ as

$\tau_{\mathrm{c}}(z)=\frac{3}{2} \frac{U_{\mathrm{LWP}}}{r_{\mathrm{e}}}$.

As our focus is mainly on boundary layer clouds, we consider only the liquid clouds. The cloud-top parameters (as one value per pixel) are then calculated by integration in the vertical as would be seen from space assuming maximum cloud overlap.

\subsection{The stratocumulus to trade cumulus transition}

Our examination is restricted to the northeastern Pacific Ocean between 0 and $40^{\circ} \mathrm{N}$ latitude and between 125 and $175^{\circ} \mathrm{W}$ longitude. A persistent stratocumulus to trade cumulus transition is bordered by deep convection in the tropics and midlatitude baroclinic systems. The highest frequency of stratocumulus occurs from June to September (Klein and Hartmann, 1993). The AIRS and MODIS instruments have provided daily and global data since late 2002 . To investigate a reasonable subset of data and minimize interannual variations, we focus on all available days in all 10 Julys from 2003 to 2012 for a total of 310 days.

The emphasis of this study is on the Global Energy and Water Cycle Experiment (GEWEX) Cloud System Study (GCSS) Pacific Cross-Section Inter-comparison (GPCI) transect (Teixeira et al., 2011) using the same area approach described by Karlsson et al. (2010); this transect is shown in Fig. 1. The track is defined by 12 boxes each with a size of $3^{\circ} \times 4^{\circ}$ (latitude $\times$ longitude). The coloring describes the frequency of low-cloud coverage for July 2003-2012 according to the International Satellite Cloud Climatology Project (ISCCP) (Rossow and Schiffer, 1999). A snapshot overlay of the MODIS visible $0.65 \mu \mathrm{m}$ channel is also shown in Fig. 1, highlighting the broken character of MBL clouds in this transitional region. These boxes are chosen as a benchmark for comparisons. The collocation of MODIS and AIRS 


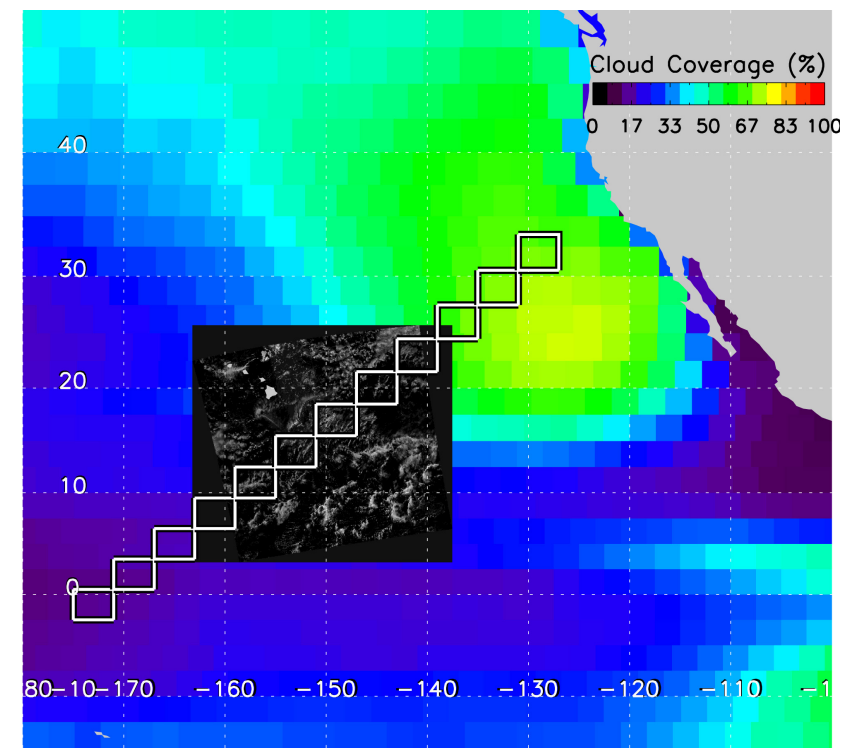

Fig. 1. Shown is the primary region of interest in the northeastern Pacific Ocean along the GPCI transect (white boxes; Karlsson et al., 2010; Teixeira et al., 2011). The colored background is the mean low-cloud amount according to ISCCP (Rossow and Schiffer, 1999) for a July composite from 2003 to 2010 . The overlay is a snapshot image from the $0.65 \mu \mathrm{m}$ channel of MODIS from 1 July 2007.

is performed on the pixel scale within these boxes, with no averaging among the boxes.

The GPCI transect contains a broad range of cloud types. The main three MBL cloud types are namely stratocumulus $(\mathrm{Sc})$, transition cumulus (trans $\mathrm{Cu}$ ) and trade cumulus (trade $\mathrm{Cu}$ ). The parameter that differentiates between these three broad MBL cloud categories is the cloud fraction, defined here as the percentage of cloudy pixels within a unit area. There is no precise definition of the spatial scale that applies to cloud coverage as a discriminant for these three cloud types. The MODIS pixel-scale variability within the AIRS FOV was used to determine cloud fraction and the resulting MBL cloud type. In addition to the three categories of MBL cloud types, three additional categories for high clouds, midlevel clouds and clear sky are included, but no further subclassification is attempted herein. The definition of each category is based on the MODIS cloud mask "confident cloud" and "probably cloud" categories and cloud-top pressure. The flag probably cloud was weighted with $50 \%$ cloudy for consistency, but changes in this weighting do not affect the results due to the low frequency of occurrence of this flag in the data sets. The definition of the cloud type within each AIRS FOV is as follows:

- trade $\mathrm{Cu}$ : cloud fraction $<30 \%$ below $680 \mathrm{hPa}$, cloud fraction $<1 \%$ for above $680 \mathrm{hPa}$ pressure level;

- trans Cu: cloud fraction 30-90\% below $680 \mathrm{hPa}$, cloud fraction $<1 \%$ for clouds above $680 \mathrm{hPa}$ pressure level;
- Sc: cloud fraction $>90 \%$ below $680 \mathrm{hPa}$, cloud fraction $<1 \%$ for clouds above $680 \mathrm{hPa}$ pressure level;

- high clouds (high cld): cloud fraction $>90 \%$ for clouds above $440 \mathrm{hPa}$ pressure level;

- mid-level clouds (mid cld): cloud fraction $>90 \%$ for clouds between $440-680 \mathrm{hPa}$;

- clear sky (clr): cloud fraction $=0 \%$.

Only homogeneous FOVs (cloud fraction $>90 \%$ ) are used in the case of mid-level and high clouds to reduce the number of complicated cloud configurations in the study. For clear sky, only the clearest scenes (cloud fraction $=0 \%$ ) are retained. Due to the cloud detection limits of MODIS (Ackerman et al., 2008), it is likely that some thin cirrus as well as subpixelscale MBL clouds not detected by the MODIS cloud mask are contained in low-cloud or clear-sky scenes, or that some low clouds were classified as mid-level clouds. However, adjustments in these definitions do not lead to any appreciable changes in the statistics that follow. Another drawback of polar-orbiting satellites that must be considered is the instantaneous observation at 13:30 LT. The time dependence of the relationship between cloud coverage, $\theta$ and $q$ cannot be taken into account by daily snapshots at a fixed local time.

The sample size of all profiles in this area exceed 1800000 for AIRS/MODIS. Around $55 \%$ of them $(1000000)$ fell into the defined cloud categories. Cloud properties were only retained when MODIS retrievals were successful within the AIRS footprint, reducing the total sample size to approximately 980000 data points. The AIRS/AMSU sounding suite encounters cloud-type-dependent sampling rates that may impact the "representativeness" of $\theta$ and $q$ statistics within each cloud regime. Only "good" quality profiles are retained; the AIRS "PGood" flag is used to indicate a good retrieval to the ocean surface. Yue et al. (2011) used CloudSat and CALIPSO to quantify the sampling rate by cloud type. AIRS has sampling rates of $80-90 \%$ in areas of trade $\mathrm{Cu}$, and as much as $20-40 \%$ within Sc regimes. In this study, approximately 900000 profiles with successful retrievals are obtained for the 310-day period. Approximately $27 \%$ of the data are found in trade $\mathrm{Cu}, 26 \%$ in trans $\mathrm{Cu}, 20 \%$ in $\mathrm{Sc}$, $18 \%$ in high clouds, $5 \%$ in mid-level clouds and $4 \%$ in clear sky.

The selection of cloud types and the time frame of analysis using ERA-Interim were determined in the exact same manner as AIRS/MODIS. The satellite overpasses during daylight are at approximately 13:30 LST (approximately 01:0004:00 UTC, depending on the location in the swath). For consistency, only the 00:00 UTC snapshots from ERA-Interim were used. If the cloud fraction of mid-level or high clouds was below $5 \%$, the cloud cover in the lower layer was used to determine the presence of clear sky, $\mathrm{Sc}$, trans $\mathrm{Cu}$, or trade $\mathrm{Cu}$. The total sample size is approximately 30000 , with $17 \%$ of the data in trade $\mathrm{Cu}, 35 \%$ in trans $\mathrm{Cu}, 32 \%$ in $\mathrm{Sc}, 11 \%$ in high clouds, $1 \%$ in mid-level clouds and $4 \%$ in clear sky. 


\subsection{Cloud-type statistics of thermodynamic profiles and cloud parameters}

AIRS retrievals of $\theta$ and $q$, as well as MODIS cloud retrievals of effective radius, cloud optical thickness and cloud-top height $\left(r_{\mathrm{e}}, \tau_{\mathrm{c}}\right.$, and $\left.T_{\mathrm{c}}\right)$, are quantified and sorted by the aforementioned cloud types, and the same procedure is followed for ERA-Interim. To quantify differences between the different cloud types, statistics of each geophysical parameter are calculated separately for each cloud type and then compared to each other. Given a group of thermodynamic profiles and cloud parameters, the mean, standard deviation, skewness and kurtosis are calculated. To take into account the influence of time variability, we show, for each data set and cloud type, two types of profiles in these statistics: first, the average from daily "snapshots" for the 310-day period, and second, the total average of all profiles from all 310 days. This is also done for the higher moments. The second moment (standard deviation) provides information about the variation from the mean. Skewness and kurtosis, the third and fourth moment, provide information about the shape of the distribution function. The skewness helps to identify asymmetry and side tails, whereas the kurtosis identifies the strength of the "peakedness" of the distribution. In the case of $\theta$ and $q$, the statistics are calculated individually for each vertical layer. This approach was taken to preserve height-dependent behavior in the PDFs. For the cloud parameters, the moments of $r_{\mathrm{e}}, \tau_{\mathrm{c}}$ and $T_{\mathrm{c}}$ are calculated for each cloud type. The interpretations assume a single mode that neglects bimodality. This is a simplified assumption, as bimodality is possible in tropical water vapor (Zhang et al., 2006) and in non-steady-state cases (Sukhutame and Young, 2010), which could have an influence on skewness and kurtosis of $q$ for trade $\mathrm{Cu}$ and high clouds. However, the analysis of randomly selected layers of $\theta$ and $q$ for the different cloud types did not reveal any bimodal distributions in our data set and the simplified unimodal assumption is used for all calculations.

AIRS and MODIS are not the only instruments of relevance in the A-train for the quantification of the statistical state of MBL clouds in the GPCI cross section. However, the wide instrument swaths (AIRS: $1600 \mathrm{~km}$, MODIS: $2330 \mathrm{~km}$ ) facilitate the robust calculation of daily instantaneous spatial statistics. The active sensors with a narrow surface track (CloudSat and CALIPSO) do not sample in swaths and thus only the synergy of AIRS and MODIS is emphasized herein.

\section{Results}

Here we describe the observational and model-derived parameters and their statistical moments. This includes the cloud-type-dependent PDFs of $r_{\mathrm{e}}, \tau_{\mathrm{c}}$ and $T_{\mathrm{c}}$ from MODIS, and the lower-tropospheric stability (LTS), $\theta$ and $q$ from AIRS.

\subsection{Cloud parameters}

Figure 2 shows the annual mean evolution of relative occurrence and frequency distribution of cloud fraction of the defined types of clouds. The occurrence (panel a) for AIRS/MODIS and (panel b) for ERA-Interim is normalized relative to clear sky: $100 \%$ translates as the same occurrence of the cloud type as clear-sky occurrence for this month, whereas 200 or $300 \%$ translate as 2 or 3 times more occurrence of this type than clear sky. We are using each July month separately and an average over all 10 July months (right of black line). On average, ERA-Interim shows a higher occurrence of low marine cloud types than observations. In ERA-Interim, Sc occurs on average 9 times more often than clear sky, whereas the observations show a factor of 6 difference. Similar differences are seen for trans $\mathrm{Cu}$ (ERA-Interim $\sim 11$, AIRS/MODIS $\sim 7$ ) and trade $\mathrm{Cu}$ (ERA-Interim 9.6, AIRS/MODIS 7.5). However, midlevel clouds (ERA-Interim $\sim 2.3$, AIRS/MODIS $\sim 2.4$ ) and high clouds (ERA-Interim $\sim 6.6$, AIRS/MODIS $\sim 6.2$ ) are remarkably similar. There is also a substantial variation from year to year, with a strong peak in 2005 and 2010 for ERAInterim and AIRS/MODIS in all cloud types. A detailed investigation of seasonal variations is beyond the scope of this article and warrants further investigation.

The PDFs of cloud fraction are shown in the panels $\mathrm{c}$ and $\mathrm{d}$ of Fig. 2. The frequency of Sc cloud amount is weighted more heavily to near $100 \%$ in MODIS compared to ERAInterim. For trade $\mathrm{Cu}$ in AIRS/MODIS, the maximum frequencies are weighted near the bottom $(0 \%)$ of their respective ranges, with a minimum around $30 \%$ cloud fraction. In contrast, ERA-Interim shows a peak frequency of occurrence around $30 \%$ cloud fraction, near the cut-off value for the definition of trade $\mathrm{Cu}$ and trans $\mathrm{Cu}$. Thus, ERA-Interim is producing a higher occurrence frequency of low clouds than observations, but with a lower magnitude of cloud fraction compared to the observations. The limited spatial resolution $(250 \mathrm{~m}$ to $1 \mathrm{~km})$ of MODIS may somewhat overestimate the trade $\mathrm{Cu}$ population in comparison to trans $\mathrm{Cu}$ or $\mathrm{Sc}$ (Zhao and Di Girolamo, 2006).

Figure 3 shows the statistical distributions of $\tau_{\mathrm{c}}, T_{\mathrm{c}}$ and $r_{\mathrm{e}}$ for each cloud type and is summarized in Table 1. A decrease in the mean $\tau_{\mathrm{c}}$ is observed from $\mathrm{Sc}$ to trade $\mathrm{Cu}$ (Fig. 3, panels $\mathrm{b}$ and $\mathrm{e}$ ), consistent with geostationary satellite observations of MBL clouds (Kawai and Teixeira, 2010). The mean values in ERA-Interim are smaller than MODIS, and the decrease of $\tau_{\mathrm{c}}$ from $\mathrm{Sc}$ to trade $\mathrm{Cu}$ is also much larger in ERAInterim. Furthermore, the skewness and kurtosis of the distributions of $\tau_{\mathrm{c}}$ are highest for trade $\mathrm{Cu}$ and lowest for $\mathrm{Sc}$ in both ERA-Interim and MODIS, also consistent with Kawai and Teixeira (2010). However, ERA-Interim has lower values of skewness and kurtosis for the distributions of $\tau_{\mathrm{c}}$ compared to MODIS, indicating a more Gaussian behavior (especially for Sc). While MODIS reports a high occurrence of low-cloud fraction below $5 \%$ (Fig. 2, panel c) it appears 

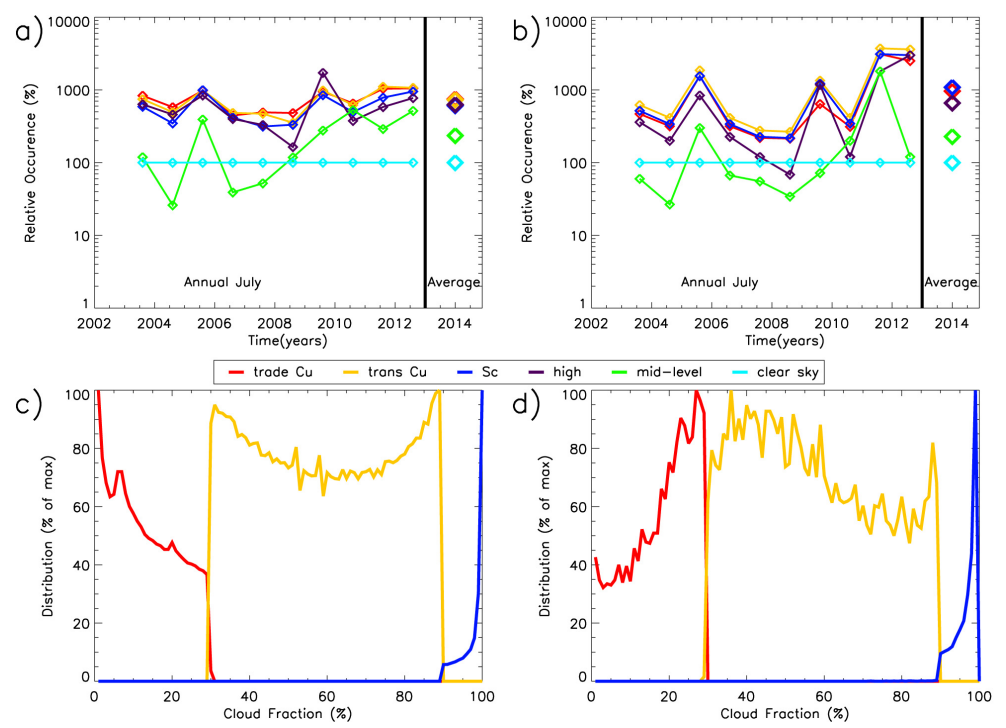

Fig. 2. Annual and average occurrence of cloud types relative to clear sky (panels a and $\mathbf{b}$ ) and cloud fraction (panels $\mathbf{c}$ and $\mathbf{d}$ ) for the entire 310-day data set. The left column is for the AIRS/MODIS observations, and the right is for ERA-Interim.

to report much lower occurrences of optically thin trade $\mathrm{Cu}$ compared to ERA-Interim (Fig. 2, panel d). The MODIS and ERA-Interim differences in the distribution of liquid water for trade and trans $\mathrm{Cu}$ suggests, in combination with the information of occurrence and cloud coverage from the paragraph before, a biased distribution of cloud liquid water and cloud coverage within ERA-Interim compared to the observations.

There are also several notable features in the $T_{\mathrm{c}}$ data (Fig. 3, panels $\mathrm{b}$ and e). The mean $T_{\mathrm{c}}$ increases from $\mathrm{Sc}$ to trade $\mathrm{Cu}$ in both data sets. While $T_{\mathrm{c}}$ increases from $286.1 \mathrm{~K}$ in $\mathrm{Sc}$ to $294.4 \mathrm{~K}$ within trade $\mathrm{Cu}$ in MODIS, ERA-Interim only shows an increase from 286.7 to $289.1 \mathrm{~K}$. This is consistent with expectations that trade $\mathrm{Cu}$ are found in lower latitudes over warm ocean surfaces compared to Sc. The overestimation of $T_{\mathrm{c}}$ from MODIS is consistent with a warm $T_{\mathrm{c}}$ bias observed in MODIS partly cloudy pixels (Marchand et al., 2010). The large negative skewness observed in $T_{\mathrm{c}}$ for trade $\mathrm{Cu}$ is seen in both MODIS and ERA-Interim and is consistent with a small population of trade $\mathrm{Cu}$ skewed towards higher and colder altitudes capped by a weak trade wind inversion, and a large population at lower and warmer altitudes. In Sc and trans $\mathrm{Cu}$, the distributions of $T_{\mathrm{c}}$ are nearly Gaussian, except for elevated kurtosis of Sc in ERA-Interim.

The mean $r_{\mathrm{e}}$ shows a substantial increase from $\mathrm{Sc}$ $(12.3 \mu \mathrm{m})$ to trade $\mathrm{Cu}(17.7 \mu \mathrm{m})$ in the MODIS data. The ERA-Interim data show only a weak increase from 11.3 to $12.3 \mu \mathrm{m}$. The larger $r_{\mathrm{e}}$ may be a result of overestimation of droplet radii in the MODIS cloud retrieval (King et al., 2013). However, it is consistent with the occurrence of larger droplets from stronger updrafts and light precipitation and/or drizzle for $r_{\mathrm{e}}$ larger than $15 \mu \mathrm{m}$ (Gerber, 1996; Masunaga et al., 2002) and is more realistic than ERA-Interim. For
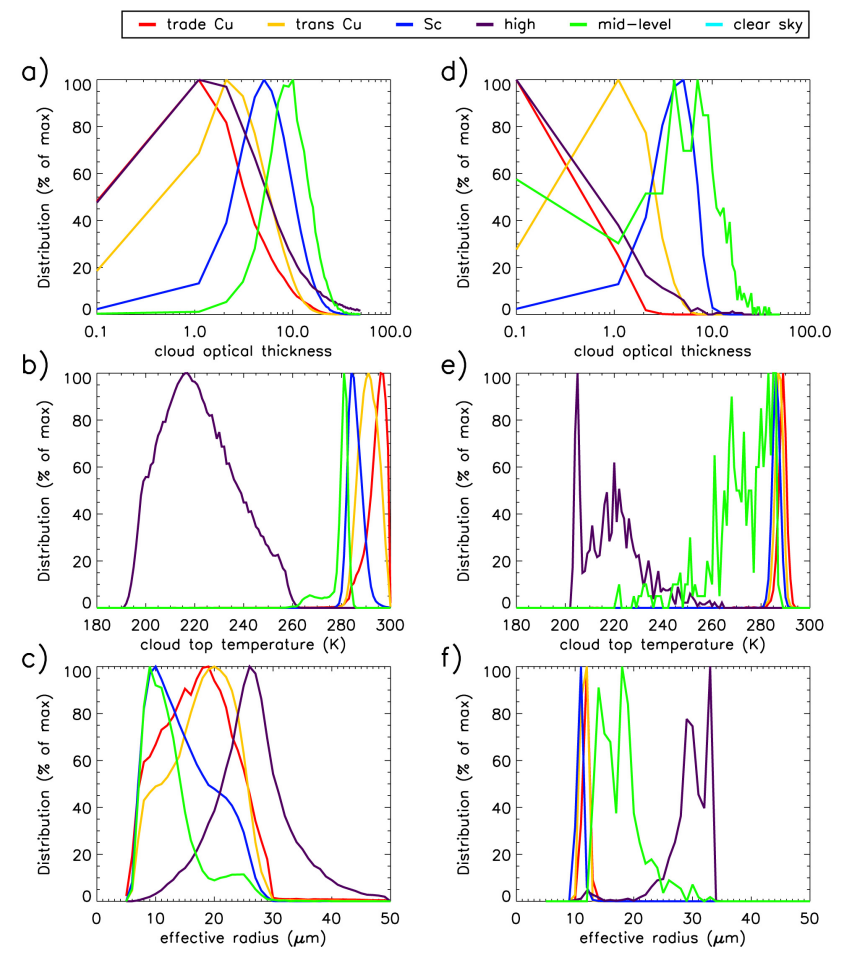

Fig. 3. Cloud-type distributions of $\tau_{\mathrm{c}}$ (panels a and d), $T_{\mathrm{c}}$ (panels $\mathbf{b}$ and e) and $r_{\mathrm{e}}$ (panels $\mathbf{c}$ and f) for the entire 310-day data set. The left column is for the AIRS/MODIS observations, and the right is for ERA-Interim.

MODIS, the $r_{\mathrm{e}}$ distribution shows a weaker skewness for trade and trans $\mathrm{Cu}$ compared to Sc. ERA-Interim has significant non-Gaussian behavior within trade $\mathrm{Cu}$ and Sc. The effective radius in ERA-Interim is calculated as a function 
Table 1. Mean, standard deviation, skewness and kurtosis of MODIS-derived ("S" for satellite columns) and ERA-Interim-derived ("M" for model columns) cloud parameters $\left(\tau_{\mathrm{c}}, r_{\mathrm{e}}, T_{\mathrm{c}}\right)$.

\begin{tabular}{|c|c|c|c|c|c|c|c|c|}
\hline \multirow[t]{2}{*}{ Cloud optical thickness } & \multicolumn{2}{|c|}{ Mean } & \multicolumn{2}{|c|}{ SD } & \multicolumn{2}{|c|}{ Skewness } & \multicolumn{2}{|c|}{ Kurtosis } \\
\hline & $\mathrm{S}$ & M & $\mathrm{S}$ & M & $\mathrm{S}$ & M & $\mathrm{S}$ & M \\
\hline Trade $\mathrm{Cu}$ & 4.5 & 0.8 & 4.1 & 0.5 & 1.9 & 1.1 & 4.8 & 2.1 \\
\hline Transition cloud & 5.0 & 2.3 & 3.3 & 1.1 & 1.8 & 1.0 & 3.9 & 1.4 \\
\hline Stratocumulus & 8.5 & 5.4 & 4.8 & 1.9 & 1.4 & 0.4 & 3.7 & 0.1 \\
\hline High clouds & 13.4 & 2.3 & 18.8 & 3.3 & 2.6 & 3.2 & 7.1 & 11.5 \\
\hline Mid-level clouds & 12.3 & 8.9 & 5.6 & 6.2 & 1.4 & 1.3 & 3.9 & 2.8 \\
\hline \multirow[t]{2}{*}{ Effective radius $(\mu \mathrm{m})$} & \multicolumn{2}{|c|}{ Mean } & \multicolumn{2}{|c|}{ SD } & \multicolumn{2}{|c|}{ Skewness } & \multicolumn{2}{|c|}{ Kurtosis } \\
\hline & $\mathrm{S}$ & M & S & M & S & M & $\mathrm{S}$ & M \\
\hline Trade $\mathrm{Cu}$ & 17.7 & 12.3 & 6.1 & 0.8 & 0.4 & 11.0 & 0.6 & 222.1 \\
\hline Transition cloud & 18.1 & 12.1 & 5.4 & 0.4 & 0.1 & -0.2 & -0.7 & -0.1 \\
\hline Stratocumulus & 12.3 & 11.3 & 5.4 & 0.5 & 1.0 & 3.7 & 0.3 & 41.5 \\
\hline High clouds & 26.9 & 30.0 & 6.6 & 3.9 & 0.3 & -0.4 & 0.7 & -1.1 \\
\hline Mid-level clouds & 13.1 & 18.4 & 5.0 & 3.8 & -5.2 & 0.3 & 0.7 & 7.0 \\
\hline \multirow[t]{2}{*}{ Cloud-top temp (K) } & \multicolumn{2}{|c|}{ Mean } & \multicolumn{2}{|c|}{ SD } & \multicolumn{2}{|c|}{ Skewness } & \multicolumn{2}{|c|}{ Kurtosis } \\
\hline & $\mathrm{S}$ & M & $S$ & M & $\mathrm{S}$ & M & $\mathrm{S}$ & M \\
\hline Trade $\mathrm{Cu}$ & 294.4 & 289.1 & 4.9 & 2.9 & 5.0 & -12.4 & 84.8 & 27 \\
\hline Transition cloud & 291.6 & 287.8 & 3.7 & 1.5 & -0.1 & -0.4 & -0.4 & 0.7 \\
\hline Stratocumulus & 286.1 & 286.7 & 2.8 & 2.8 & 0.6 & -1.4 & 0.7 & 2.9 \\
\hline High clouds & 222.4 & 222.2 & 15.0 & 16.6 & 0.4 & 1.6 & -0.6 & 5.1 \\
\hline Mid-level clouds & 280.4 & 270.8 & 4.6 & 14.8 & -2.3 & -0.4 & 4.0 & -1.2 \\
\hline
\end{tabular}

of height. As a result, the highly non-Gaussian behavior of $r_{\mathrm{e}}$ in ERA-Interim data implies that this simple approach for parameterizing $r_{\mathrm{e}}$ is insufficient for the representation of a realistic PDF of $r_{\mathrm{e}}$.

The largest variations of $T_{\mathrm{c}}$ that occur within high clouds $(\sigma=15.5 \mathrm{~K}$ for MODIS and 16.6 K for ERA-Interim) is expected because of the wider variety of cloud formations within the less restrictive latitude range $\left(0-40^{\circ} \mathrm{N}\right)$. Smaller variations of mid-level clouds are found in MODIS data $(\sigma=4.6 \mathrm{~K})$, whereas the variations in ERA-Interim are much larger $(\sigma=14.8)$. A more detailed inspection of the vertical distribution of clouds reveals that ERA-Interim is distributing the clouds across more height bins between 440 and $680 \mathrm{hPa}$ compared to MODIS. The largest $r_{\mathrm{e}}$ is found for high clouds $(26.9 \mu \mathrm{m})$ in the MODIS data, while the midlevel clouds have significantly smaller $r_{\mathrm{e}}(13.1 \mu \mathrm{m})$ that is very similar to $r_{\mathrm{e}}$ found in Sc. The occurrence of large $r_{\mathrm{e}}$ in high clouds relative to liquid clouds is consistent with extensive in situ and remote sensing observations. In ERA-Interim, the $r_{\mathrm{e}}$ for high $(30.0 \mu \mathrm{m})$ and mid-level clouds $(18.4 \mu \mathrm{m})$ is similar to MODIS. However, the distribution functions show that ERA-Interim data, unlike MODIS, are bimodal.

Overall, the shapes of the PDFs for $T_{\mathrm{c}}, \tau_{\mathrm{c}}$ and $r_{\mathrm{e}}$ are substantially different from each other between the cloud types and between observations and ERA-Interim. Significant differences among the cloud types are observed in the mean val- ues with additional differences in the extent of the PDF tails. Therefore, defining a single PDF shape for all cloud parameters is difficult. PDFs should take into account the changes from $\mathrm{Sc}$ via trans $\mathrm{Cu}$ towards trade $\mathrm{Cu}$. In our study, the main parameter for the cloud types is the cloud fraction; thus, we propose to use a PDF which includes the cloud fraction as a variable. Also, the PDFs for MODIS and ERA-Interim show a few remarkable similarities: for instance, similar skewness and kurtosis of the $T_{\mathrm{c}}$ distribution for trade $\mathrm{Cu}$. Some notable differences are the ERA-Interim estimates of $r_{\mathrm{e}}$, which are related to an overly simplified approach to calculating $r_{\mathrm{e}}$ compared to MODIS. Differences are also observed for small values of cloud fraction near the limits of MODIS observational capabilities. Thus, the behavior of the PDFs may partly result from retrieval characteristics such as assumed constraints on minima and maxima of the cloud parameters.

\subsection{Lower-tropospheric stability}

The lower-tropospheric stability (LTS) is defined as the difference between the potential temperature at $700 \mathrm{hPa}$ and the surface (Klein and Hartmann, 1993) and is proposed as one possibility to constrain cloud fraction in models (Slingo, 1980). Figure 4 shows the distributions of LTS for the three categories of MBL clouds and clear sky from AIRS (panel a) and ERA-Interim (panel b), and Table 2 summarizes the statistical moments. Figure 4 shows that the variation of LTS 


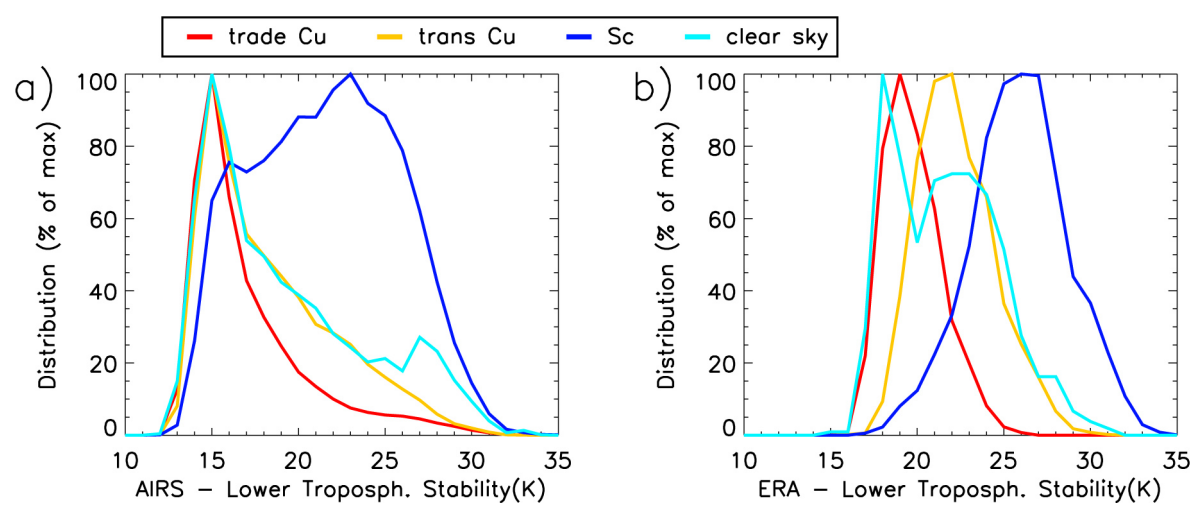

Fig. 4. Cloud-type distributions of lower-tropospheric stability for the entire 310-day data set. Panel (a) is for the AIRS/MODIS observations, and panel (b) for ERA-Interim.

Table 2. Mean, standard deviation, skewness and kurtosis of AIRS-derived lower-tropospheric stability (LTS) for three marine boundary layer (MBL) cloud types and clear sky (defined in Sect. 2).

\begin{tabular}{lrrrrrrrrr}
\hline Lower-trop. stability (K) & \multicolumn{3}{c}{ Mean } & \multicolumn{2}{c}{ SD } & \multicolumn{2}{c}{ Skewness } & \multicolumn{2}{c}{ Kurtosis } \\
\cline { 2 - 10 } & S & M & S & M & S & M & S & M \\
\hline Trade Cu & 17.2 & 22.2 & 3.4 & 1.7 & 1.1 & 1.0 & 2.3 & 1.8 \\
Transition cloud & 18.1 & 23.6 & 3.7 & 1.5 & 0.6 & 0.5 & 0.0 & 1.1 \\
Stratocumulus & 22.5 & 25.9 & 4.1 & 1.8 & -0.2 & 1.7 & 0.1 & 0.0 \\
Clear sky & 25.1 & 24.2 & 4.9 & 4.3 & 0.3 & 0.4 & 0.5 & -0.9 \\
\hline
\end{tabular}

within Sc in observed data is much higher than in ERAInterim data. The mean AIRS LTS shows a decrease from Sc to trade $\mathrm{Cu}$, consistent with expectations of increasing stability in Sc regions. The ERA-Interim LTS shows somewhat higher mean values, and a larger jump between trans $\mathrm{Cu}$ and $\mathrm{Sc}$ than between trade $\mathrm{Cu}$ and trans $\mathrm{Cu}$; this is also true in AIRS LTS. The mean LTS in clear sky is $\sim 1 \mathrm{~K}$ higher in AIRS compared to ERA-Interim. The positive skewness for trade $\mathrm{Cu}$ in both observations and ERA-Interim indicates that the "positive tail" of the trade Cu distribution into high LTS may be realistic; this could indicate the presence of opencellular convection in regions that would otherwise be Sc. This topic could be investigated further with the use of highresolution MODIS visible channels. The comparably large skewness and kurtosis for ERA-Interim in the case of clear sky is partly caused by the bimodal behavior of the distribution and is absent in MODIS/AIRS. It appears that ERAInterim is often producing clear-sky conditions for LTS values where the observations show trade $\mathrm{Cu}$ development.

\subsection{Temperature profiles}

Vertical profiles of $\theta$ and $q$ are obtained from the 100-layer AIRS L2 support product and from ERA-Interim. For the AIRS observations, the examination of the statistical properties of $\theta$ and $q$ not only suggests differences related to cloud type but also highlights a few potential, yet subtle, cloud-type-dependent retrieval artifacts. The four moments of $\theta$ and their day-to-day variability obtained from AIRS and ERA-Interim are shown in Fig. 5 (mean and standard deviation) and Fig. 6 (skewness and kurtosis). The two left columns show the profiles from 200 to $1000 \mathrm{hPa}$, while the two right columns show the layers from 800 to $1000 \mathrm{hPa}$ to highlight the detail of the MBL. As expected, the mean profiles of $\theta$ are similar for all cloud types in the free troposphere, while more significant differences are found below $850 \mathrm{hPa}$ and near the tropopause. The inversion is observed for $\mathrm{Sc}$, trans $\mathrm{Cu}$ and clear sky around $850-900 \mathrm{hPa}$ in ERAInterim. In AIRS, rather than observing a sharp inversion, a slight change in lapse rate is seen in the case of Sc and trans $\mathrm{Cu}$. The coarse vertical resolution of AIRS may not be able to resolve weak and vertically shallow inversions in the lower troposphere, especially in the presence of Sc, but reasonable results are observed for lower values of cloud fraction (trans and trade $\mathrm{Cu}$ ).

In the upper row of Fig. 5, the daily averages (solid lines) are very similar to the total average (dashed lines) in both AIRS and ERA-Interim. AIRS $\theta$ profiles have a much higher variability in all cases, even in clear sky, for which AIRS is expected to have maximum skill. In the MBL, AIRS has a lower standard deviation of $\theta\left(\sigma_{\theta}\right)$ for trade $\mathrm{Cu}$ compared to Sc. ERA-Interim shows similar magnitudes for all MBL clouds for the daily averages, but a much smaller standard deviation for the total average. This shows that the variability 

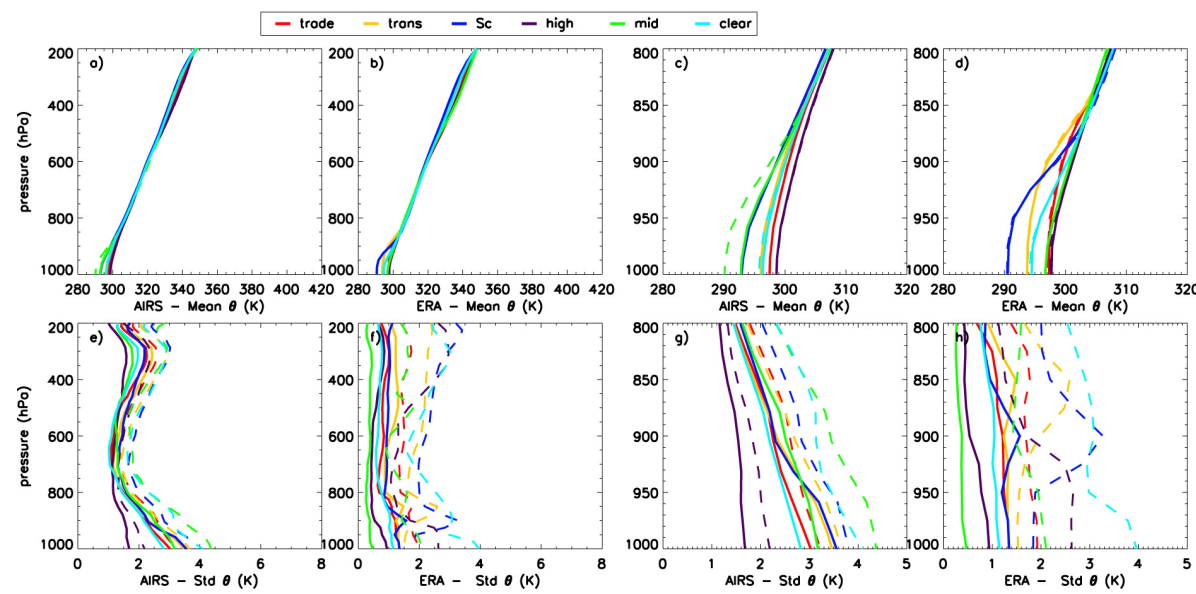

Fig. 5. The mean (panels a to d), standard deviation (panels e and $\mathbf{h}$ ) of the vertical profile of $\theta$ obtained from averages of the 310 -day daily snapshots (solid line) and from all profiles (dashed line). Panels (a) and (e) show AIRS/MODIS observations from 200 to $1000 \mathrm{hPa}$, and panels (c) and (g) show the same AIRS/MODIS observations from 800 to $1000 \mathrm{hPa}$. ERA-Interim is shown in panels (b), (d), (f) and (h).

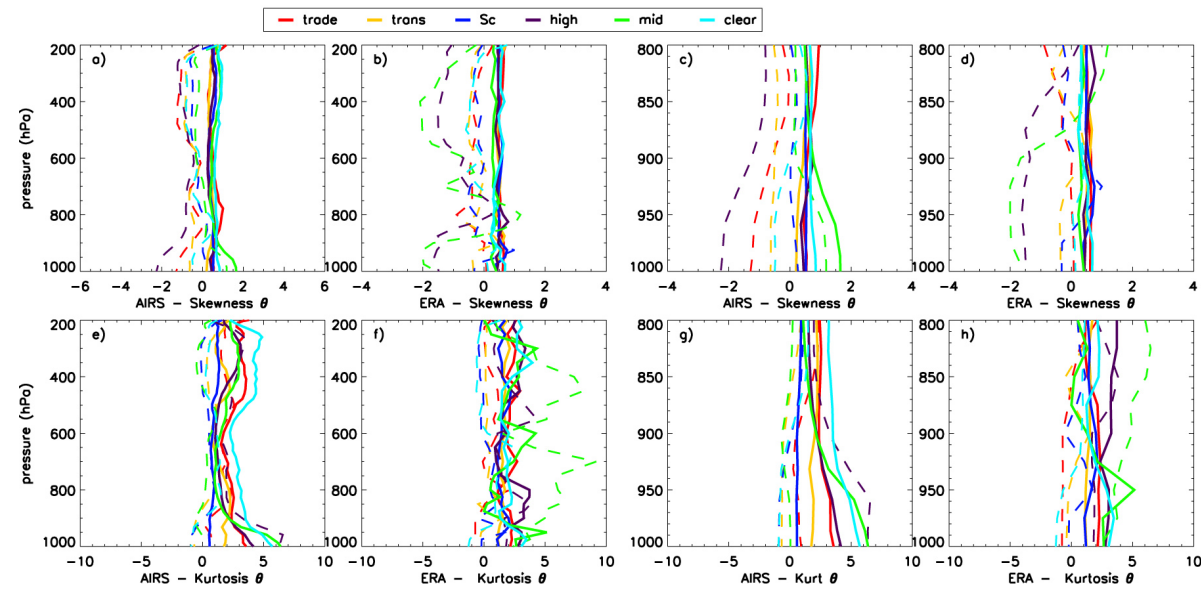

Fig. 6. The same as Fig. 5 except for the skewness and kurtosis.

is driven to a large extent by time variations and not spatial variations, unlike AIRS, which is primarily driven by spatial variations. In general, $\sigma_{\theta}$ is largest in the MBL and near the tropopause for all cloud types in both AIRS and ERAInterim. For high clouds, low values of $\sigma$ are observed in the MBL and near 250-300 hPa. On average, approximate Gaussian behavior of $\theta$ is observed for most of the ERA-Interim profiles; this is suggested by low values of skewness and kurtosis and random oscillations along the vertical profile. The exception is in the MBL, where a slightly higher variability in the higher moments is visible. Similar Gaussian behavior is observed for AIRS data in the case of Sc and trans $\mathrm{Cu}$. Daily averages show a negative skewness for almost all cases, whereas the total skewness is close to zero. However, the kurtosis has a strong positive tendency in the satellite data in the MBL that is not seen in ERA-Interim.

AIRS cannot accurately resolve the fine vertical detail of the MBL (Maddy and Barnet, 2008). However, these results demonstrate a systematic change in the distributional characteristics of $\theta$ between the MBL and free troposphere in both clear and cloudy sky compared to ERA-Interim. Overall, the observations by AIRS show structured patterns in the profile of the higher moments, whereas the variability is more random in the ERA-Interim data. This suggests that AIRS is resolving MBL structures that ERA-Interim is not capturing despite the known reduced sensitivity of AIRS in the lower troposphere and within the presence of high values of cloud fraction. Furthermore, a closer examination shows significant differences for the cloud types. First, $\sigma_{\theta}$ is lower and more uniform for trans $\mathrm{Cu}$ than for $\mathrm{Sc}$ and trade $\mathrm{Cu}$ between 1000 and $850 \mathrm{hPa}$. Second, skewness and kurtosis for trans $\mathrm{Cu}$ and trade $\mathrm{Cu}$ near the surface show an increase within the boundary layer and a decrease in the free troposphere. As a modeling benchmark to test these behaviors, Zhu and Zuidema (2009) used field campaign data from eight experiments to simulate MBL structure with a 

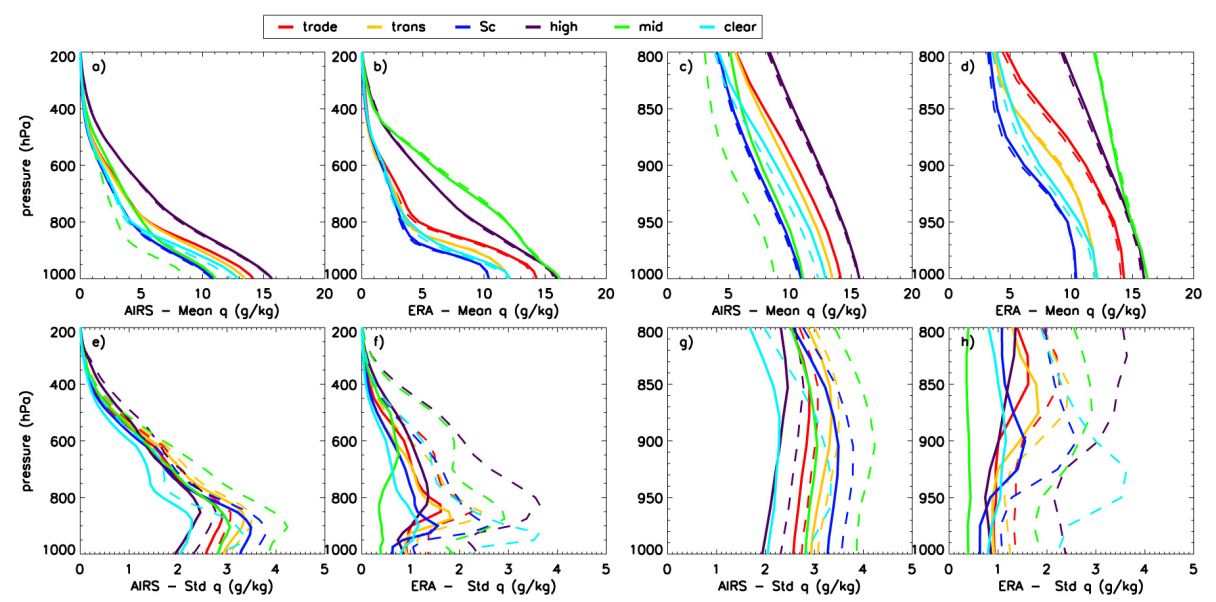

Fig. 7. The same as Fig. 5 except for the vertical profile of water vapor mixing ratio $(\mathrm{g} / \mathrm{kg})$.

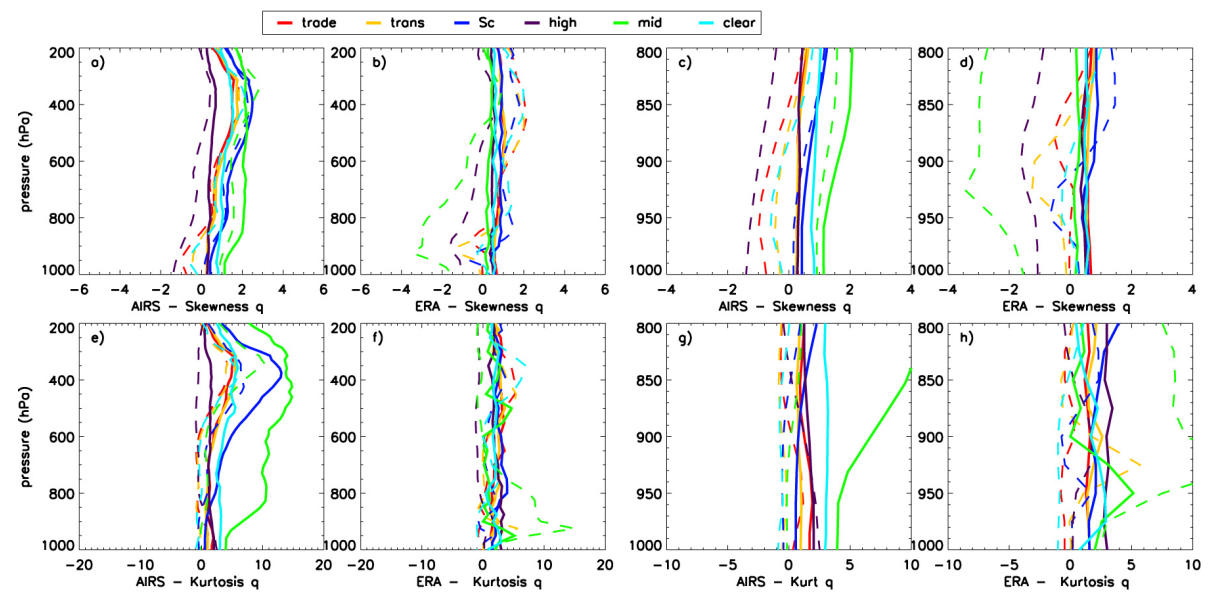

Fig. 8. The same as Fig. 6 except for the vertical profile of water vapor mixing ratio $(\mathrm{g} / \mathrm{kg})$.

cloud-resolving model. They obtained large vertical variations in the statistics of liquid water potential temperature $\left(\theta_{1}\right)$, total water mixing ratio $\left(q_{\mathrm{t}}\right)$, and vertical velocity over the depth of the cloud layer. A comparison of Zhu and Zuidema (2009) with AIRS suggests similarities of $\theta_{1}$ and $\theta$ in positive skewness of observed high clouds, similar to the positive skewness seen in the simulations of the above authors. However, with respect to low clouds, AIRS cannot resolve the strong gradients at the top of the broken cloud layers shown in Zhu and Zuidema (2009), and this highlights the importance of obtaining higher-vertical-resolution thermodynamic soundings than currently available from infrared and microwave satellite sounding.

\subsection{Water vapor profiles}

The statistical moments of $q$ are summarized in Figs. 7 and 8 . For AIRS, the mean profiles of $q$ show drier conditions for Sc and trans $\mathrm{Cu}$ than for trade $\mathrm{Cu}$ and clear sky and are less well mixed in the lowest levels. ERA-Interim and AIRS/MODIS show very similar magnitudes and relative ordering of average $q$ sorted by MBL cloud type. AIRS shows a weaker transition from the well-mixed boundary layer to the free troposphere in the mean profiles, similar to what we have seen already in the temperature profiles. Again, this is indication that the weakness of the current AIRS retrieval is the low sensitivity in the boundary layer caused by limits in the AIRS vertical resolution (Maddy and Barnet, 2008). The "average" profiles show a smoothed mean boundary layer profile of $q$. However, the higher moments are more sensitive to the deviations from the average, and we can quantify their behavior in the boundary layer with high confidence based on previous work (e.g., Kahn et al., 2011b; Yue et al., 2011). As expected, the standard deviation of $q\left(\sigma_{q}\right)$ in Fig. 7, panel e, is higher in the MBL compared to the free troposphere for all AIRS cloud types. In the MBL (panel $\mathrm{g}$ ), $\sigma_{q}$ is relatively low for clear sky and increasing from trade $\mathrm{Cu}$ to trans $\mathrm{Cu}$ to $\mathrm{Sc}$. A subtle but notable feature in the AIRS data is a slight increase in $\sigma_{q}$ around $800-900 \mathrm{hPa}$ (depending on the MBL cloud type), 
which coincides with the upper portion of the MBL near the base of the inversion. The ERA-Interim in panel $h$ shows a similar but sharper gradient, which supports the assertion that AIRS is capable of capturing relative differences in the vertical structure of $\sigma_{q}$.

There is also a notable difference between AIRS and ERAInterim in the case of mid-level cloud in Fig. 7. ERA-Interim profiles have a much higher mean value and standard deviation of $q$. There are two possible reasons for this. First, the comparison of ERA-Interim with MODIS cloud data showed biases for mid-level clouds in ERA-Interim. ERA-Interim mid-level clouds appear more frequently compared to observations (Fig. 3), and the higher values of $q$ are consistent with their occurrence in low latitudes. Second, we restricted AIRS to "PGood" profiles with $<=90 \%$ cloud fraction. This limits the sample size and can result in an observational bias for the thickest clouds. This warrants a more detailed investigation of mid-level clouds in future work.

The skewness of AIRS and ERA-Interim (Fig. 8, panels a and b) is slightly positive for all cloud types and pressure levels on a daily average, but slightly negative for an overall skewness that accounts for time variations. The AIRS profiles show an increase of this positive skewness within the free troposphere, similar to the kurtosis of $\theta$. This increase is larger for $\mathrm{Sc}$ and trans $\mathrm{Cu}$ than for clear-sky and trade $\mathrm{Cu}$ cases, indicating that the lower latitudes, where trade $\mathrm{Cu}$ and clear sky occur, have stronger positively skewed profiles. ERA-Interim is almost constant throughout the troposphere, with slightly reduced values in the MBL. The kurtosis of $q$ shows high variations for AIRS observations. A large increase is observed from $\mathrm{Sc}$ to trade $\mathrm{Cu}$ at $400 \mathrm{hPa}$. A qualitative comparison of AIRS $q$ to $q_{\mathrm{t}}$ in Zhu and Zuidema (2009) is partly justified, as water vapor is the dominant component of $q_{\mathrm{t}}$. An increase in skewness of $q_{\mathrm{t}}$ with altitude is observed in Zhu and Zuidema (2009), consistent with observations of $q$ from AIRS. Furthermore, Iassamen et al. (2009) obtained statistical moments of $q$ from a ground-based microwave profiler over land, dividing measurements into cloudy and clear cases. Similar variations in skewness and kurtosis of $q$ for cloud and clear-sky cases in the microwave measurements and AIRS profiles are seen. Overall, the AIRS data, Zhu and Zuidema (2009), and Iassamen et al. (2009) collectively point towards a non-Gaussian cloud-type behavior of $q$ not observed in ERA-Interim.

\section{Conclusions}

A novel pixel-scale application of cloud properties and thermodynamic profiles obtained from the NASA Aqua MODerate resolution Imaging Spectroradiometer (MODIS) and Atmospheric Infrared Sounder (AIRS) is presented for a subtropical cloud regime transition in the northeastern Pacific Ocean. Simultaneous observations of cloud properties, potential temperature $(\theta)$ and water vapor $(q)$ profiles are quan- tified by cloud type for all available July days from 2003 to 2012. A collocation method that uses the prelaunch spatial response functions of AIRS is used to obtain robust cloudtype estimates within the AIRS field of view using MODIS cloud products. Cloud-type-dependent estimates of the statistical properties of clouds and thermodynamic profiles are quantified. The focus is within the northeastern Pacific Ocean summertime along the GPCI cross section, a region well known for a persistent stratocumulus to trade cumulus transition. This marine boundary layer cloud transition is considered to be highly relevant to observational and model assessments of climate sensitivity. Individual AIRS FOVs are sorted into stratocumulus ( $\mathrm{Sc}$ ), transition cumulus (trans $\mathrm{Cu}$ ), and trade cumulus (trade $\mathrm{Cu}$ ), mid-level and high clouds, and clear sky. The mean, standard deviation, skewness and kurtosis of the cloud fields and thermodynamic profiles are obtained separately for each cloud type. AIRS and MODIS probability density functions (PDFs) are compared to similarly derived PDFs obtained from the ERA-Interim reanalysis.

The analysis of the observed PDFs and their higher moments suggests the following:

- The average occurrence of MBL clouds relative to clear sky is higher in ERA-Interim than in the observations from MODIS.

- Cloud fraction distributions are significantly different within the trade $\mathrm{Cu}$, trans $\mathrm{Cu}$ and $\mathrm{Sc}$ cloud-type categories between MODIS and ERA-Interim.

- The distribution of $T_{\mathrm{c}}$ for trade $\mathrm{Cu}$ in AIRS/MODIS has higher and more strongly skewed values than ERA-Interim

- A strong skewness in the LTS of low clouds is seen in observations.

- LTS shows a PDF with strong skewness and bimodal shape for clear-sky cases in the ERA-Interim data, which is not seen in observations.

- Clear sky and trade Cu both exhibit non-Gaussian behavior of $\theta$ in observations, which is weaker in ERAInterim

- For $q$, reductions in the standard deviations are observed in the MBL in ERA-Interim and observations.

- A positive skewness and kurtosis of $q$ in the free troposphere is seen for observations but not for ERAInterim.

- Both ERA-Interim and observations tend to have similar vertical structures, but an overall reduced magnitude in the standard deviation of ERA-Interim is noted. 
Table 3. Acronyms and symbols used in text.

\begin{tabular}{ll}
\hline$q$ & water vapor mixing ratio \\
$q_{\mathrm{t}}$ & total water mixing ratio \\
$\theta$ & potential temperature \\
$\theta_{\mathrm{l}}$ & liquid potential temperature \\
$T_{\mathrm{c}}$ & cloud-top temperature \\
$r_{\mathrm{e}}$ & cloud effective radius \\
$\tau_{\mathrm{c}}$ & cloud optical thickness \\
$\mathrm{LTS}$ & lower-tropospheric stability \\
$\sigma_{\mathrm{q}}$ & standard deviation of water vapor mixing ratio \\
$\sigma_{\theta}$ & standard deviation of potential temperature \\
\hline
\end{tabular}

- ERA-Interim shows reduced magnitudes in skewness and kurtosis, indicating a more Gaussian behavior than observations.

Knowing the distributional characteristics of cloud and thermodynamic properties for different types of clouds is necessary for implementing a subgrid-scale parameterization of cloud processes in climate models. The results obtained from the synergistic, pixel-scale MODIS and AIRS observations offer important constraints on the spatial, temporal and cloud-type variability in these PDFs.

Future work will include an extension of this method to other MBL transitional regimes, as well as an expansion to other cloud regimes throughout the seasonal cycles over the NASA Aqua observing record.

Acknowledgements. Funding for this project was provided by NASA award NNX08AI09G. The authors would like to thank J. Teixeira and the AIRS project at the Jet Propulsion Laboratory for encouragement and support. MODIS data were obtained through the Level-1 and Atmosphere Archive and Distribution System (LAADS; http://ladsweb.nascom.nasa.gov/). AIRS data were obtained through the Goddard Earth Sciences Data and Information Services Center (http://daac.gsfc.nasa.gov). A portion of this work was performed within the Joint Institute for Regional Earth System Science \& Engineering (JIFRESSE) of the University of California, Los Angeles (UCLA), and at the Jet Propulsion Laboratory, California Institute of Technology, under contract with NASA. We also would like to thank the reviewers for their valuable comments, which considerably helped in improving the quality of the manuscript.

The JPL author's copyright for this publication is held by the California Institute of Technology. Government sponsorship is also acknowledged.

Edited by: A. Geer

\section{References}

Ackerman, S. A., Holz, R. E., Frey, R., Eloranta, E. W., Maddux, B. C., and McGill, M.: Cloud detection with MODIS. Part II: Validation, J. Atmos. Ocean. Tech., 25, 1073-1086, 2008.

Ahlgrimm, M. and Köhler, M.: Evaluation of trade cumulus in the ECMWF model with observations from CALIPSO, Mon. Weather Rev., 138, 3071-3083, 2010.

Albrecht, B. A., Bretherton, C. S., Johnson, D., Scubert, W. H., and Frisch, A. S.: The Atlantic Stratocumulus Transition Experiment-ASTEX, B. Am. Meteorol. Soc., 76, 889-904, 1995.

Aumann, H. H., Chahine, M. T., Gautier, C., Goldberg, M., Kalnay, E., McMillin, L., Revercomb, H., Rosenkranz, P. W., Smith, W. L., Staelin, D., Strow, L., and Susskind, J.: AIRS/AMSU/HSB on the aqua mission: Design, science objectives, data products, and processing systems, IEEE T. Geosci. Remote, 41, 253-264, 2003.

Barnes, W. L., Pagano, T. S., and Salomonson, V. V.: Prelaunch characteristics of the Moderate Resolution Imaging Spectroradiometer (MODIS) on EOS-AM1, IEEE T. Geosci. Remote, 36, 1088-1100, 1998.

Bogenschutz, P. A., Gettelman, A., Morrison, H., Larson, V. E., Craig, C., and Schanen, D. P.: Higher-Order Turbulence Closure and Its Impact on Climate Simulations in the Community Atmosphere Model, J. Climate, 26, 9655-9676, doi:10.1175/JCLI-D13-00075.1, 2013.

Bony, S. and Dufresne, J.-L.: Marine boundary layer clouds at the heart of tropical cloud feedback uncertainties in climate models, Geophys. Res. Lett., 32, L20806, doi:10.1029/2005GL023851, 2005.

Cess, R. D., Potter, G. L., Blanchet, J. P., Boer, G. J., Ghan, S. J., Kiehl, J. T., Treut, H. L., Li, Z.-X., Liang, X.-Z., Mitchell, J. F. B., Morcrette, J.-J., Randall, D. A., Riches, M., Roeckner, E., Schlesse, U., Slingo, A., Taylor, E. E., Washington, W. M., Wetherald, R. T., and Yagai, I.: Interpretation of cloud-climate feedback as produced by 14 atmospheric general circulation models, Science, 245, 513-516, 1989.

Cess, R. D., ,Zhang, M. H., Ingram, W. J., Potter, G. L., Alekseev, V., Barker, H. W., Cohen-Solal, E., Colman, R. A., Dazlich, D. A., Del Genio, A. D., Dix, M. R., Dymnikov, V., Esch, M., Fowler, L. D., Fraser, J. R., Galin, V., Gates, W. L., Hack, J. J., Kiehl, J. T., Le Treut, H., Lo, K. K.-W., McAvaney, B. J., Meleshko, V. P., Morcrette, J.-J., Randall, D. A., Roeckner E., Royer, J.-F., Schlesinger, M. E., Sporyshev, P. V., Timbal, B., Volodin, E. M., Taylor, K. E., Wang, W., and Wetherald, R. T.: Cloud feedback in atmospheric general circulation models: An update, J. Geophys. Res., 101, 12791-12794, doi:10.1029/96JD00822, 1996.

Cuijpers, J. W. M., and Bechtold, P.: A simple parameterization of cloud water related variables for use in boundary layer models, J. Atmos. Sci., 52, 2486-2490, 1995.

Dee, D. P., Uppala, S. M., Simmons, A. J., Berrisford, P., Poli, P., Kobayashi, S., Andrae, U., Balmaseda, M. A., Balsamo, G., Bauer, P., Bechtold, P., Beljaars, A. C. M., van de Berg, L., Bidlot, J., Bormann, N., Delsol, C., Dragani, R., Fuentes, M., Geer, A. J., Haimberger, L., Healy, S. B., Hersbach, H., Hólm, E. V., Isaksen, L., Kållberg, P., Köhler, M., Matricardi, M., McNally, A. P., Monge-Sanz, B. M., Morcrette, J.-J., Park, B.-K., Peubey, C., de Rosnay, P., Tavolato, C., Thépaut, J.-N., and Vitart, F.: The 
ERA-Interim reanalysis: configuration and performance of the data assimilation system, Q. J. Roy Meteor. Soc., 137, 553-597, doi:10.1002/qj.828, 2011.

Frey, R. A., Ackerman, S. A., Liu, Y., Strabala, K. I., Zhang, H., Key, J. R., and Wang, X.: Cloud detection with MODIS. Part I: Improvements in the MODIS cloud mask for Collection 5, J. Atmos. Ocean. Tech., 25, 1057-1072, 2008.

Gerber, H.: Microphysics of marine stratocumulus clouds with two drizzle modes, J. Atmos. Sci., 53, 1649-1662, 1996.

Gierens, K., Kohlhepp, R., Dotzek, N., and Smit, H. G.: Instantaneous fluctuations of temperature and moisture in the upper troposphere and tropopause region. Part 1: Probability densities and their variability, Meteorol. Z., 16, 221-231, 2007.

Guo, H., Golaz, J.-C., Donner, L. J., Larson, V. E., Schanen, D. P., and Griffin, B. M.: Multi-variate probability density functions with dynamics for cloud droplet activation in large-scale models: single column tests, Geosci. Model Dev., 3, 475-486, doi:10.5194/gmd-3-475-2010, 2010.

Hartmann, D., Ockert-Bell, M., and Michelsen, M.: The effect of cloud type on Earth's energy balance: Global analysis, J. Climate, 5, 1281-1304, 1992.

Iassamen, A., Sauvageot, H., Jeannin, N., and Ameur, S.: Distribution of tropospheric water vapor in clear and cloudy conditions from microwave radiometric profiling, J. Appl. Meteorol., 48, 600-615, 2009.

IFS documentation, Cy31r1, Part IV: physical processes, http://www.ecmwf.int/research/ifsdocs/CY31r1/PHYSICS/ IFSPart4.pdf (last access: 2 January 2014), 2007.

IPCC, Climate Change 2007: The Physical Science Basis. Contribution of Working Group I to the Fourth Assessment Report of the Intergovernmental Panel on Climate Change, edited by: Solomon, S., Qin, D., Manning, M., Chen, Z., Marquis, M., Averyt, K. B., Tignor, M., and Miller, H. L., Cambridge University Press, Cambridge, United Kingdom and New York, NY, USA, 2007.

Kahn, B. H, Nasiri, S. L., Schreier, M. M., and Baum, B. A.: Impacts of sub-pixel cloud heterogeneity on infrared thermodynamic phase assessment, J. Geophys. Res., D20201, doi:10.1029/2011JD015774, 2011a.

Kahn, B. H., Teixeira, J., Fetzer, E. J., Gettelman, A., HristovaVeleva, S. M., Huang, X., Kochanski, A. K., Köhler, M., Krueger, S. K., Wood, R., and Zhao, M.: Temperature and Water Vapor Variance Scaling in Global Models: Comparisons to Satellite and Aircraft Data, J. Atmos. Sci., 68, 2156-2168, doi:10.1175/2011JAS3737.1, 2011b.

Karlsson, J., Svensson, G., Cardoso, S., Teixeira, J., and Paradise, S.: Subtropical Cloud-Regime Transitions: Boundary Layer Depth and Cloud-Top Height Evolution in Models and Observations, J. Appl. Meteorol., 49, 1845-1858, 2010.

Kawai, H. and Teixeira, J.: Probability density functions of liquid water path and cloud amount of marine boundary layer clouds: Geographical and seasonal variations and controlling meteorological factors, J. Climate, 23, 2079-2092, 2010.

King, N. J., Bower, K. N., Crosier, J., and Crawford, I.: Evaluating MODIS cloud retrievals with in situ observations from VOCALS-RE ${ }_{\mathrm{x}}$, Atmos. Chem. Phys., 13, 191-209, doi:10.5194/acp-13-191-2013, 2013.

Klein, S. A. and Hartmann, D. L.: The seasonal cycle of low stratiform clouds, J. Climate, 6, 1587-1606, 1993.
Lambrigtsen, B. H. and Lee, S.-Y.: Coalignment and synchronization of the AIRS instrument suite, IEEE T. Geosci. Remote, 41, 343-351, 2003.

Larson, V. E., Wood, R., Field, P. R., Golaz, J.-C., Vonder Haar, T. H., and Cotton, W. R.: Small-Scale and mesoscale variability of scalars in cloudy boundary layers: One-dimensional probability density functions, J. Atmos. Sci., 58, 1978-1994, 2001.

Lewis, E. R., Wiscombe, W. J., Albrecht, B. A., Bland, G. L., Flagg, C. N., Klein, S. A., Kollias, P., Mace, G., Reynolds, R. M., Schwartz, S. E, Siebesma, A. P., Teixeira, J., Wood, R., and Zhang, M.: MAGIC: Marine ARM GPCI Investigation of Clouds, Environmental Sciences, DOE/SC-ARM-12-020, http://www.osti.gov/scitech/servlets/purl/1052589 (last access: 1 April 2014), 2012.

Li, J., Menzel, W. P., Sun, F., Schmit, T. J., and Gurka, J.: AIRS subpixel cloud characterization using MODIS cloud products, J. Appl. Meteorol., 43, 1083-1094, 2004a.

Li, J., Menzel, W. P., Zhang, W., Sun, F., Schmit, T. J., Gurka, J. J., and Weisz, E.: Synergistic use of MODIS and AIRS in a variational retrieval of cloud parameters, J. Appl. Meteorol., 43, 1619-1634, 2004b.

Maddy, E. S. and Barnet, C. D.: Vertical resolution estimates in version 5 of AIRS operational retrievals. IEEE T. Geosci. Remote, 46, 2375-2384, 2008

Maddy, E. S., King, T. S., Sun, H., Wolf, W. W., Barnet, Heidinger, A., Cheng, Z., Goldberg, M. D., Gambacorta, A., Zhang, C., and Zhang, K.: Using Metop-A AVHRR clear-sky measurements to cloud-clear Metop-A ISAI column radiances, J. Atmos. Ocean. Tech., 28, 1104-1116, doi:10.1175/JTECH-D-10-05045.1, 2011.

Marchand, R., Ackerman, T., Smyth, M., and Rossow, W. B.: A review of cloud top height and optical depth histograms from MISR, ISCCP, and MODIS, J. Geophys. Res., 115, D16206, doi:10.1029/2009JD013422, 2010

Martins, J. P. A., Teixeira, J., Soares, P. M. M., Miranda, P. M. A., Kahn, B. H., Dang, V. T., Irion, F. W., Fetzer, E. J., and Fishbein, E.: Infrared sounding of the trade-wind boundary layer: AIRS and the RICO experiment, Geophys. Res. Lett., 37, L24806, doi:10.1029/2010GL045902, 2011.

Masunaga, H., Nakajima, T. Y., Nakajima, T., Kachi, M., and Suzuki, K.: Physical properties of maritime low clouds as retrieved by combined use of Tropical Rainfall Measuring Mission (TRMM) Microwave Imager and Visible/Infrared Scanner, 2. Climatology of warm clouds and rain, J. Geophys. Res., 107, 4367, doi:10.1029/2001JD001269, 2002.

Medeiros, B., Stevens, B., Held, I. M., Zhao, M., Williamson, D. L. Olson, J. G., and Bretherton, C. S.: Aquaplanets, climate sensitivity, and low clouds, J. Climate, 21, 4974-4991, 2008.

Menzel, W. P., Baum, B. A., Strabala, K. I., and Frey, R. A.: Cloud top properties and cloud phase, MODIS Algorithm Theoretical Basis Document, 2006.

Nasiri, S. L., Dang, H. V. T., Kahn, B. H., Fetzer, E. J., Manning, E. M., Schreier, M. M., and Frey, R. A.: Comparing MODIS and AIRS infrared-based cloud retrievals, J. Appl. Meteorol. Clim., 50, 1057-1072, 2011.

Norris, J. R.: Low cloud type over the ocean from surface observations. Part I: relationship to surface meteorology and the vertical distribution of temperature and moisture, J. Climate, 11, 369382, 1998. 
Ou, S.-C., Kahn, B. H., Liou, K. N., Takano, Y., Schreier, M. M., and Yue, Q.: Retrieval of cirrus cloud properties from the Atmospheric Infrared Sounder: The k-coefficient approach combined with SARTA plus delta-four stream approximation, IEEE T. Geosci. Remote, 1010-1024, 2013.

Overoye, K., Aumann, H. H., Weiler, M. H., Gigioli, G. W., Shaw, W., Frost, E., and McKay, T.: Test and Calibration of the AIRS instrument, SPIE Proceedings, 3759, 254-265, 1999.

Pincus, R., and Klein, S. A.: Unresolved spatial variability and microphysical process rates in large-scale models, J. Geophys. Res., 105, 27059-27065, 2000.

Platnick, S., King, M. D., Ackerman, S. A., Menzel, W. P., Baum, B. A., Riédi, J. C., and Frey, R. A.: The MODIS cloud products: Algorithms and examples from Terra, IEEE T. Geosci. Remote, 41, 459-473, 2003.

Pressel, K. G. and Collins, W. D.: First order structure function analysis of statistical scale invariance in the observed AIRS water vapor field, J. Climate, 25, 5538-5555, 2012.

Price, J. D., and Wood, R.: Comparison of probability density functions for total specific humidity and saturation deficit humidity, and consequences for cloud parameterization, Q. J. Roy. Meteor. Soc., 128, 2059-2072, 2002.

Quaas, J.: Evaluating the "critical relative humidity" as a measure of subgrid-scale variability of humidity in general circulation model cloud cover parameterizations using satellite data, J. Geophys. Res, 117, D09208, doi:10.1029/2012JD017495, 2012.

Randall, D. A.: Beyond deadlock, Geophys. Res. Lett., 40, 59705976, doi:10.1002/2013GL057998, 2013.

Rossow, W. B. and Schiffer, R. A.: Advances in Understanding Clouds from ISCCP, B. Am. Meteorol. Soc., 72, 2-20, 1999,

Schreier, M. M., Kahn, B. H., Eldering, A., Elliott, D. A., Fishbein, E., Irion, F. W., and Pagano, T. S.: Radiance comparisons of MODIS and AIRS using spatial response information, J. Atmos. Ocean. Tech., 27, 1331-1342, 2010.

Slingo, J. M.: A cloud parametrization scheme derived from GATE data for use with a numerical model, Q. J. Roy. Meteor. Soc., 106, 747-770, doi:10.1002/qj.49710645008, 1980.

Sommeria, G. and Deardorff, J. W.: Subgrid-scale condensation in models of nonprecipitating clouds, J. Atmos. Sci., 34, 344-355, 1977.

Stephens, G. L.: Cloud feedbacks in the climate system: A critical review, J. Climate, 18, 237-273, 2005.

Stevens, B.: Atmospheric Moist Convection, Annu. Earth Planet. Sci., 32, 605-643, 2005.

Stevens, B., Lenschow, D. H., Vali, G., Gerber, H., Bandy, A., Blomquist, B., Brenguier, J.-L., Bretherton, C. S., Burnet, F., Campos, T., Chai, S., Faloona, I., Friesen, D., Haimov, S., Laursen, K., Lilly, D. K., Loehrer, S. M., Malinowski, S. P., Morley, B., Petters, M. D., Rogers, D. C., Russell, L., SavicJovcic, V., Snider, J. R., Straub, D., Szumowski, M. J., Takagi H., Thornton, D. C., Tschudi, M., Twohy, C., Wetzel M., and van Zanten, M. C.: Dynamics and Chemistry of Marine Stratocumulus-DYCOMS-II, B. Amer. Meteorol. Soc., 84, 579593, doi:10.1175/BAMS-84-5-579, 2003.

Su, H., Jiang, J. H., Vane, D. G., and Stephens, G. L.: Observed vertical structure of tropical oceanic clouds sorted in large-scale regimes, Geophys. Res. Lett., 35, L24704, doi:10.1029/2008GL035888, 2008.
Sukhatme, J. and Young, W. R.:The advection-condensation model and water vapour PDFs, Q. J. Roy. Meteorol. Soc., 137, 15611572, doi:10.1002/qj.869, 2010.

Susskind, J., Barnet, C. D., and Blaisdell, J. M.: Retrieval of atmospheric and surface parameters from AIRS/AMSU/HSB data in the presence of clouds, IEEE T. Geosci. Remote, 41, 390-409, 2003.

Susskind, J., Barnet, C., Blaisdell, J., Iredell, L., Keita, F., Kouvaris, L., Molnar, G., and Chahine, M.: Accuracy of geophysical parameters derived from Atmospheric Infrared Sounder/Advanced Microwave Sounding Unit as a function of fractional cloud cover, J. Geophys. Res., 111, D09S17, doi:10.1029/2005JD006272, 2006.

Teixeira, J., Cardoso, S., Bonazzola, M., Cole, J., DelGenio, A., DeMott, C., Franklin, C., Hannay, C., Jakob, C., Jiao, Y., Karlsson, J., Kitagawa, H., Koehler, M., Kuwano-Yoshida, A., Ledrian, C., Lock, A., Miller, M. J., Marquet, P., Martins, J., Mechoso, C. R., Meijgaard, E. V., Meinke, I., Miranda, P. M. A., Mironov, D., Neggers, R., Pan, H. L., Randall, D. A., Rasch, P. J., Rockel, B., Rossow, W. B., Ritter, B., Siebesma, A. P., Soares, P., Turk, F. J., Vaillancourt, P., Von Engeln, A., and Zhao, M.: Tropical and subtropical cloud transitions in weather and climate prediction models: the GCSS/WGNE Pacific Crosssection Inter-comparison (GPCI), J. Climate, 24, 5223-5256, doi:10.1175/2011JCLI3672.1, 2011.

Tobin, D. C., Revercomb, H. E., Moeller, C. C., and Pagano, T. S.: Use of AIRS high spectral resolution spectra to assess the calibration of MODIS on EOS Aqua, J. Geophys. Res., 111, D09S05, doi:10.1029/2005JD006095, 2006.

Tompkins, A. M.: Impact of temperature and humidity variability on cloud cover assessed using aircraft data. Q. J. Roy. Meteorol Soc., 129, 2151-2170, doi:10.1256/qj.02.190, 2003.

Uppala, S. M., KÅllberg, P. W., Simmons, A. J., Andrae, U., Bechtold, V. D. C., Fiorino, M., Gibson, J. K., Haseler, J., Hernandez, A., Kelly, G. A., Li, X., Onogi, K., Saarinen, S., Sokka, N., Allan, R. P., Andersson, E., Arpe, K., Balmaseda, M. A., Beljaars, A. C. M., Berg, L. V. D., Bidlot, J., Bormann, N., Caires, S., Chevallier, F., Dethof, A., Dragosavac, M., Fisher, M., Fuentes, M., Hagemann, S., Hólm, E., Hoskins, B. J., Isaksen, L., Janssen, P. A. E. M., Jenne, R., Mcnally, A. P., Mahfouf, J.-F., Morcrette, J.-J., Rayner, N. A., Saunders, R. W., Simon, P.,Sterl, A., Trenberth, K. E., Untch, A., Vasiljevic, D., Viterbo, P., and Woollen, J.: The ERA-40 re-analysis, Q. J. Roy. Meteorol. Soc., 131, 2961-3012, doi:10.1256/qj.04.176, 2005.

Vial, J., Dufresne, J.-L., and Bony, S.: On the interpretation of intermodel spread in CMIP5 climate sensitivity estimates, Clim. Dynam., 41, 3339-3362, 2013.

Weber, T., Quaas, J., and Räisänen, R.: Evaluation of the statistical cloud scheme in the ECHAM5 model using satellite data, Q. J. Roy. Meteorol. Soc., 137, 2079-2091, 2011.

Williams, K. D. and Webb, M. J.: A quantitative performance assessment of cloud regimes in climate models. Clim. Dynam., 33, 141-157, doi:10.1007/s00382-008-0443-1, 2009.

Wood, R., and Bretherton, C. S.: On the relationship between stratiform low cloud cover and lower-tropospheric stability, J. Climate, 19, 6425-6432, 2006.

Wyant, M. C., Bretherton, C. S., Bacmeister, J. T., Kiehl, J. T., Held, I. M., Zhao, M., Klein, S. A., and Soden B. J.: A comparison of low-latitude cloud properties and their response to cli- 
mate change in three AGCMs sorted into regimes using midtropospheric vertical velocity, Climate Dynam., 27, 261-279, doi:10.1007/s00382-006-0138-4, 2006.

Yue, Q., Kahn, B. H., Fetzer, E. J., and Teixeira, J.: Relationship between oceanic boundary layer clouds and lower tropospheric stability observed by AIRS, CloudSat, and CALIOP, J. Geophys. Res., 116, D18212, doi:10.1029/2011JD016136, 2011.

Yue, Q., Fetzer, E., Kahn, B., Wong, S., Manipon, G., Guillaume, A., and Wilson, B.: Cloud-state-dependent Sampling in AIRS Observations based on CloudSat Cloud Classification, J. Climate, 26, 8357-8377, doi10.1175/JCLI-D-13-00065.1, 2013.
Zhang, C., Mapes, B. E., and Soden, B. J.: Bimodality in tropical water vapor, Q. J. Roy. Meteorol. Soc., 129, 2847-2866, 2006.

Zhao, G. and Di Girolamo, L.: Cloud fraction errors for trade wind cumuli from EOS-Terra instruments, Geophys. Res. Lett., 33, L20802, doi:10.1029/2006GL027088, 2006.

Zhu, P. and Zuidema, P.: On the use of PDF schemes to parameterize sub-grid clouds, Geophys. Res. Lett., 36, L05807, doi:10.1029/2008GL036817, 2009. 